Volume 10, No.4, July - August 2021

International Journal of Advanced Trends in Computer Science and Engineering

Available Online at http://www.warse.org/IJATCSE/static/pdf/file/ijatcse091042021.pdf

https://doi.org/10.30534/ijatcse/2021/091042021

\title{
Development of Novel Predictive Models For Estimation of Nitrogen Fixation Under Cultural and Field Conditions Using R Software
}

\author{
Divya Sindhu ${ }^{1 *}$, Ekta Hooda ${ }^{2}$, Saurabh Sindhu ${ }^{3}$ and S. K. Yadav ${ }^{4}$ \\ ${ }^{1 *}$ Deptt. of Computer Science and Engineering, Shri J.J.T.U., Jhunjhunu, India, divya.sindhu91@ @mail.com \\ ${ }^{2}$ Deptt. of Mathematics \& Statistics, CCS Haryana Agric. University, Hisar, India, ektahooda @ gmail.com \\ ${ }^{3}$ Deptt. of Computer Science, Shri J.J.T.U., Jhunjhunu, Rajasthan, India, sindhu.saurabh04@ gmail.com \\ ${ }^{4}$ Professor, Deptt. of Computer Science and Engineering, Shri J.J.T.U., Jhunjhunu, India, drskyadav@ hotmail.com
}

\begin{abstract}
Farmers apply chemical fertilizers in the field soil to provide nitrogen and phosphorus nutrients for improving growth and yield of crop plants to provide food for ever-increasing human population. But, injudicious use of these chemical fertilizers results in environmental pollution and causes public health hazards. Recently, various nitrogen-fixing microorganisms are used as biofertilizers to reduce the application of chemical fertilizers. However, the survival and nitrogen $\left(\mathrm{N}_{2}\right)$ fixation capacity of these microorganisms is adversely affected under stress conditions in recent changing agroclimatic scenario. In the present study, predictive models were developed to study biological nitrogen fixation (BNF) behaviour of rhizobia in response to exogenous nitrogen $(\mathrm{N})$ level conditions under culture as well as in the soil using $\mathrm{R}$ software. With increase in concentration of ammonium $\left(\mathrm{NH}_{4}{ }^{+}\right)$or nitrate $\left(\mathrm{NO}_{3}{ }^{-}\right)$(represented along $\mathrm{X}$ axis in the graph) in the cultural medium, there is sequential fall in nitrogenase activity of Rhizobium strain 32H1 (on Y axis). Under field conditions, the comparisons of fertilizer addition showed that $\mathrm{N}_{2}$ fixation was partially suppressed after addition of $150 \mathrm{~kg} \mathrm{~N}$ per hactare in faba bean (Vicia faba) and chickpea (Cicer arietinum) species under glasshouse pots trial conditions. Predictive models were developed using $\mathrm{R}$ software to indicate the approximate values of nitrogen fixation in chickpea and faba bean under field and glasshouse conditions with application of different doses of fertilizers. These linear and non-linear predictive models could be applied to predict behaviour of nitrogen-fixing rhizobia in response to available nitrogen level under cultural as well as field conditions.
\end{abstract}

Keywords : Chemical fertilizers, Cultural and field conditions, Nitrogen fixation, Nitrogen-fixing organisms, Predictive models, R software, Rhizobia

\section{INTRODUCTION}

Expensive chemical fertilizers are added in the soil to improve yield of crop plants for providing food to the world's rapidly growing population. However, excessive use of these chemical fertilizers has polluted soil, air and water along with public health hazards [1]. Moreover, agricultural soils are continuously losing their chemical and biological health due to excessive application of fertilizers [2]. Therefore, attempts are being made recently to minimize the use of potentially deleterious agrochemicals to crop plants. In integrated nutrient management system, nitrogen-fixing microorganisms including Rhizobium species are being used as biofertilizers to improve agriculture productivity and for restoration of sustainability in agricultural systems [3], [4]. Rhizobium strains form nitrogen-fixing nodules on legume plants and reduce atmospheric nitrogen to plant utilizable ammonia for crop plants using the nitrogenase enzyme. Legume-Rhizobium symbiotic association has been reported to reduce about $70-80 \%$ of the total $17.2 \times 10^{7}$ tonnes of biologically fixed nitrogen annually on worldwide basis [5], [6]. Interestingly, inoculation of legumes with effective and competitive strains of rhizobia caused significant increases in the yield of different legume crops [7], [8].

However, the persistence, survival, nodulation capacity and the nitrogen fixation capacity of inoculated Rhizobium strains in soil were governed by various soil ecological factors such as salinity, acidity, temperature, soil moisture, aeration and osmotic stress conditions [9]-[11]. In addition, inhibitory effect of combined nitrogen (added as fertilizer) was likewise observed on root nodule formation by Azorhizobium caulinodans on Sesbania rostrata [12]. Pankhurst and Craig [13] reported that high concentrations of both $\mathrm{NH}_{4}{ }^{+}$and $\mathrm{NO}_{3}{ }^{-}$ (at $20 \mathrm{mM}-\mathrm{N}$ ) caused inhibition of nitrogenase activity by Rhizobium strain $32 \mathrm{H} 1$ under cultural conditions. Besides this, biological nitrogen fixation was also suppressed under field conditions with addition of fertilizer $\mathrm{N}$ (at $150 \mathrm{~kg} \mathrm{~N}$ per hectare dose) in Melaleuca alternifolia plantation intercropped with either chickpea or faba bean legumes [14]. Addition of $150 \mathrm{~kg} \mathrm{~N}$ fertilizer for every hactare caused $40 \%$ $\mathrm{BNF}$ reduction in faba bean and $35 \% \mathrm{BNF}$ reduction in chickpea [14].

Considering the importance of nitrogen fixation for different legume crops, extensive analysis is required to understand the contibution of nitrogen fixation by rhizobia under soil conditions. Recently, three groups of quantitative models including simple equations, coarse-grained models and detailed metabolic models have been developed for analysis and prediction of nitrogen fixation by $\mathrm{N}_{2}$-fixing organisms in terrestrial ecosystems [15]. These models have been used to complement the laboratory experiments and in situ measurements of $\mathrm{N}_{2}$ fixation [15], [16]. Different modeling strategies and mathematical theories were used in these models to interpret observations of fixed $\mathrm{N}$ uptake for making predictions about their influence on $\mathrm{N}_{2}$ fixation by free-living or symbiotic organisms, where laboratory data are missing. In this study, novel predictive models were developed using $\mathrm{R}$ software to predict nitrogen fixation by rhizobia in response to nitrogen-sufficient conditions (after fertilizer addition) in soil. This study will supplement 
laboratory experiments for improving nitrogen fixation in legumes, leading to reduction of chemical fertilizers for sustainable agriculture.

\section{MATERIALS AND METHODS}

Rhizobium species form nitrogen-fixing nodules on roots of various leguminous plants. Under favourable nitrogenlimited and microaerobic conditions in the soil or in root nodules, nitrogenase enzyme converts environmental inert nitrogen to plant utilizable ammonia. NifA protein acts as a transcriptional activator of different nitrogen fixation genes [17]-[19].

\subsection{Effect of environmental factors on nitrogen fixation by Rhizobium species under cultural and field conditions}

Nitrogen fixation in the culture medium or in the soil is adversely affectd by various ecological factors including salinity, temperature, soil moisture and addition of combined nitrogen sources. The data obtained from these parameters could be used for modeling or prediction of nitrogen fixation. Besides this, field observations and in situ measurements of nitrogen fixation are highly valuable for modeling in biological experiments. The outstanding problems faced during laboratory studies and field observations are usually resolved by development of predictive models by selecting the key parameters, which affect nitrogen fixation.

\subsubsection{Effect of combined nitrogen sources addition on nitrogenase activity}

The effect of oxygen concentration, temperature and combined nitrogen was studied on morphology and nitrogenase activity of Rhizobium sp. strain 32H1 in agar culture [13]. The primary data regarding adverse effect of addition of nitrogen sources i.e. ammonium and nitrate on nitrogenase activity of Rhizobium strain under cultural conditions was used in development of predictive model using R software. Supply of $2 \mathrm{mM}-\mathrm{N}$ to rhizobial cells (in the form of $\mathrm{NH}_{4}^{+}$) was demonstrated to support high levels of nitrogenase activity. In this study, the values reported at four concentrations i.e., 2.0, 4.0, 10.0 and $20.0 \mathrm{mM}-\mathrm{N}$ (Table 1) were further splitted into ten different concentrations with same trend of decrease in nitrogenase activity. Similarly, the addition of nitrate doses were further splitted into ten different $\mathrm{NO}_{3}{ }^{-}$concentrations with equal level of decrease in nitrogenase activity. Interestingly, the addition of $20 \mathrm{mM}-\mathrm{N}$ either as $\mathrm{NH}_{4}^{+}$and $\mathrm{NO}_{3}{ }^{-}$in culture medium was found to completely inhibit nitrogenase activity of cultured Rhizobium strain $32 \mathrm{H} 1$.

\subsubsection{Effect of nitrogenous fertilizer addition on nitrogenase activity and shoot $N$ content}

In this study, The impact of four rates of nitrogenous fertilizer addition (i.e., 0, 50, 100 and $150 \mathrm{~kg} \mathrm{~N}$ for every hactare) was studied on nitrogen fixation in faba bean (Vicia faba) and chickpea (Cicer arietinum) under glasshouse pot trial conditions [14]. The primary data values regarding effect of fertilizer addition at four concentration doses in chickpea were used for development of predictive models. The reported values of fertilizer addition were further splitted into sixteen different concentrations with same trend of decrease in shoot fixed nitrogen content. As per experimental observations, around 35 and $23 \%$ nitrogen fixation was maintained in chickpea in the field and glasshouse conditions, respectively after addition of $150 \mathrm{~kg} \mathrm{~N}$ per hectare of the soil [14]. In case of faba bean crop, the values reported for fertilizer addition at four concentration doses i.e., 0, 50, 100 and $150 \mathrm{Kg} \mathrm{N} \mathrm{ha}^{-1}$ (Table 1), were also further splitted to sixteen different concentrations with same trend of decrease in shoot fixed nitrogen content. About $40 \%$ nitrogen fixation was maintained in faba bean at $150 \mathrm{Kg} \mathrm{N} \mathrm{ha}^{-1}$ addition in the field and glasshouse conditions.

\subsection{Development of predictive model for usage in nitrogen fixation}

Predictive models were developed, using R software [20] available on the internet, for prediction of nitrogen fixation by rhizobia in response to nitrogen level conditions prevailing in culture or soil conditions. R software is freely distributed software package for statistical analysis and graphics. R can be downloaded from internet site of CRAN. $\mathrm{R}$ language is generally used among analysts and data miners for developing statistical software and data analysis. Statisticians and data miners generally use $\mathrm{R}$ software for developing statistical software, statistical computing and data analysis.

\subsubsection{Entry of data in the software}

Data can be directly entered into R software, but MS Excel is commonly used to create a data set. Data sets are arranged with every section representing a variable and each row representing to subject; a data set with 05 variables recorded on 50 subjects would be represented in Excel document with 05 columns and 50 rows. Excel can save files in 'comma delimited arrangement', or .csv files; these .csv files can then be read into $\mathrm{R}$ for analysis.

\subsubsection{Execution and analysis of data using $R$ software}

$\mathrm{R}$ is an interactive statistical computing language. During use of R software, a blank window shows up with '>', which is ready prompt, on first line of window. Analysis are performed through series of commands; user enters a command and $\mathrm{R}$ software responds. User then enters next command and $\mathrm{R}$ responds. In this software, documents, commands typed by user are given in red and responses from $\mathrm{R}$ are given in blue. $\mathrm{R}$ uses this same shading scheme. Some supportive odds and ends, when using R software include:

(i) When object name is entered, it will generally print that object.

(ii) This software is case sensitive. Hence, object named "Group" must be referred to as "Group". It ought not be entered as "group".

(iii) To recall and scroll through past commands, up and down arrow keys can be used, which can save typing when fixing grammatical mistakes or changing command.

(iv) Entering letter and afterward hitting Tab key twice, will list commands and objects beginning with that letter.

(v) Material can be cut and pasted into or from $\mathrm{R}$ window. $\mathrm{R}$ results could be saved and may print as part of MS Word documents. The text of $\mathrm{R}$ session could be saved as record of work finished.

(vi) R text is generally designed as Courier font. Courier 9 point font generally works well for R output. 


\section{RESULTS}

Three groups of quantitative models i.e., simple equations, coarse-grained models and detailed metabolic models are generally applied for exploring the nitrogen fixation in $\mathrm{N}_{2^{-}}$ fixing organisms [15]. The computation becomes less efficient and model-data comparisons become harder in the different types of models with increase in complexity of metabolic processes. The growth and elemental stoichiometry of the cells serves as the basic parameters for calculation of their effect on the rate of $\mathrm{N}_{2}$ fixation in simplest category of ecological models [21]. More detailed physiologies of nitrogen-fixing cells than simple analytical equations are included in coarse-grained models, which may resolve fewer metabolic pathways [22]. On the other hand, the most extensively studied models used in laboratories include metabolic (physiological) models, which have been developed around "model organisms". In these quantitative models, modeling strategies are applied to explore the effect of fixed $\mathrm{N}$ uptake and its influence on $\mathrm{N}_{2}$ fixation by freeliving or symbiotic organisms in terrestrial ecosystem [23][24].

\subsection{Development of statistical models for prediction of nitrogen fixation in response to addition of fertilizer containing nitrate or ammonium}

Abiotic stress conditions, especially lack or excess of appropriate nutrients (i.e, nitrogen, phosphorus, potassium), scaricity or abundance of moisture and extreme temperatures during growth season have been reported to reduce crop yields substantially. In this study, adverse effects of combined nitrogen in soil (added as fertilizers) were analyzed on the nitrogen fixation activity of nitrogenase enzyme. Computational models were developed for predicting nitrogen fixation behaviour of rhizobia in response to nitrogen level conditions prevailing in soil using $\mathrm{R}$ software [20].

\subsubsection{Effect of added nitrogen compounds on nitrogen fixation by Rhizobium species}

Pankhurst and Craig [13] reported that concentration of three nitrogen sources (i.e., glutamine, ammonium or nitrate) adversely influenced the nitrogenase activity of Rhizobium strain $32 \mathrm{H} 1$ under cultural conditions. Supply of $2 \mathrm{mM}-\mathrm{N}$ ammonium was found to support high levels of nitrogenase activity by rhizobial cells (Table 1, Figure 1), but addition of $\mathrm{NO}_{3}{ }^{-}$supported only very low nitrogenase activity (Table 2, Figure 2). However, addition of $20 \mathrm{mM}-\mathrm{N}$ either as $\mathrm{NH}_{4}{ }^{+}$and $\mathrm{NO}_{3}{ }^{-}$in culture medium was found to completely inhibit nitrogenase activity.

The following exponential model was used for prediction of $\mathrm{N}_{2}$ fixation (Table 1) from exogeneous ammonium and nitrogenase activities and for prediction of nitrogen fixation (Table 2) from nitrate addition.

$\mathrm{Y}=\mathrm{A} \exp [-\mathrm{BX}]$, where the parameter $\mathrm{A}$ represents the value of $Y$ when $X=0$ and $B$ represents the relative change in $\mathrm{Y}$ for a unit change in $\mathrm{X}$. Summary of the models fitted using $\mathrm{R}$ software has also been pasted in the respective tables.

Based on the amount of ammonium supplied in the medium as ammonium sulphate, which were further splitted to ten different concentrations with same trend of decrease in nitrogenase activity, quantitative models was developed to explore the effect of fixed $\mathrm{N}$ uptake and its influence on $\mathrm{N}_{2}$ fixation by Rhizobium species (Table 1, Figure 1). Mathematical theories were used in these quantitative models to interpret observations and predictions were made, where laboratory data are missing. Thus, using graph presented in this model, the approximate values of nitrogenase activities (along Y axis) can be predicted at different concentrations of ammonium incorporated in the medium (along $\mathrm{X}$ axis).

Table 1. Effect of exogenous ammonium addition on nitrogenase activity ( $\mathrm{N}_{2}$ fixation) in Rhizobium sp. and delopment of predictive model using $\mathrm{R}$ software

\begin{tabular}{|c|c|c|}
\hline $\begin{array}{l}\text { Concentration as } \\
\text { ammonium } \\
\text { (ammonium sulphate) }\end{array}$ & $\begin{array}{l}\text { Nitrogenase r activity } \\
{[\text { nmole }} \\
\text { reduced } h^{-1} \text { (mg protein) } \\
\left.{ }^{1}\right]\end{array}$ & \multirow{11}{*}{ 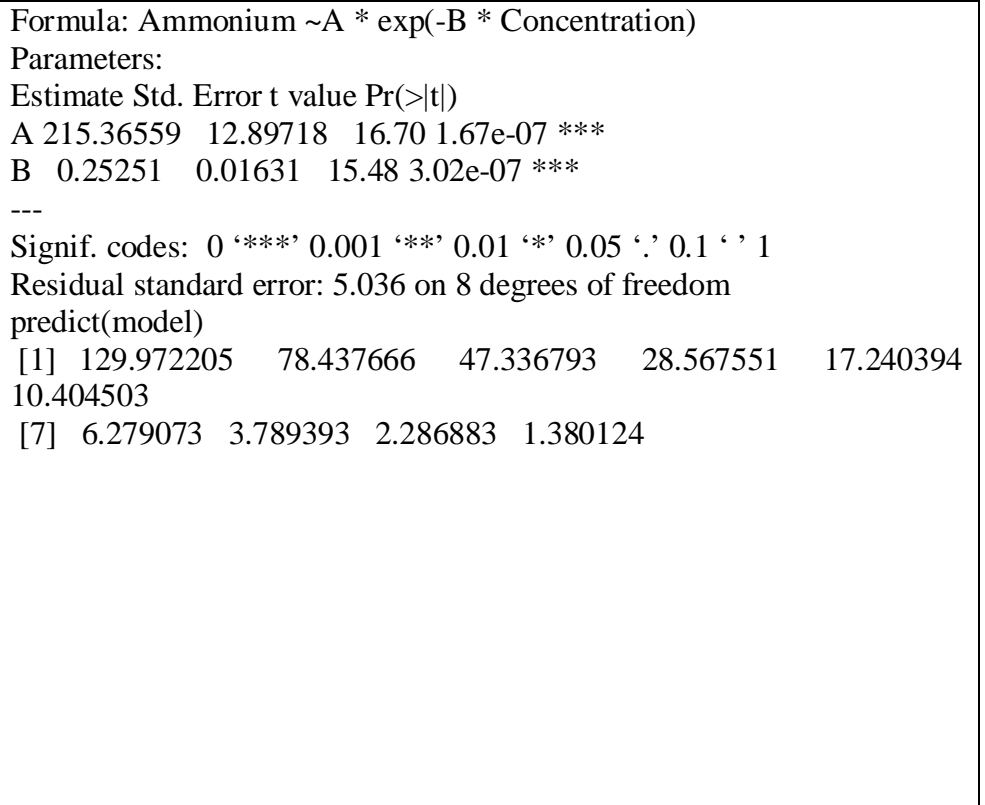 } \\
\hline 2.0 & 125.8 & \\
\hline 4.0 & 85.2 & \\
\hline 6.0 & 54.5 & \\
\hline 8.0 & 22.0 & \\
\hline 10.0 & 11.8 & \\
\hline 12.0 & 8.0 & \\
\hline 14.0 & 5.0 & \\
\hline 16.0 & 2.0 & \\
\hline 18.0 & 0.5 & \\
\hline 20.0 & 0.0 & \\
\hline
\end{tabular}




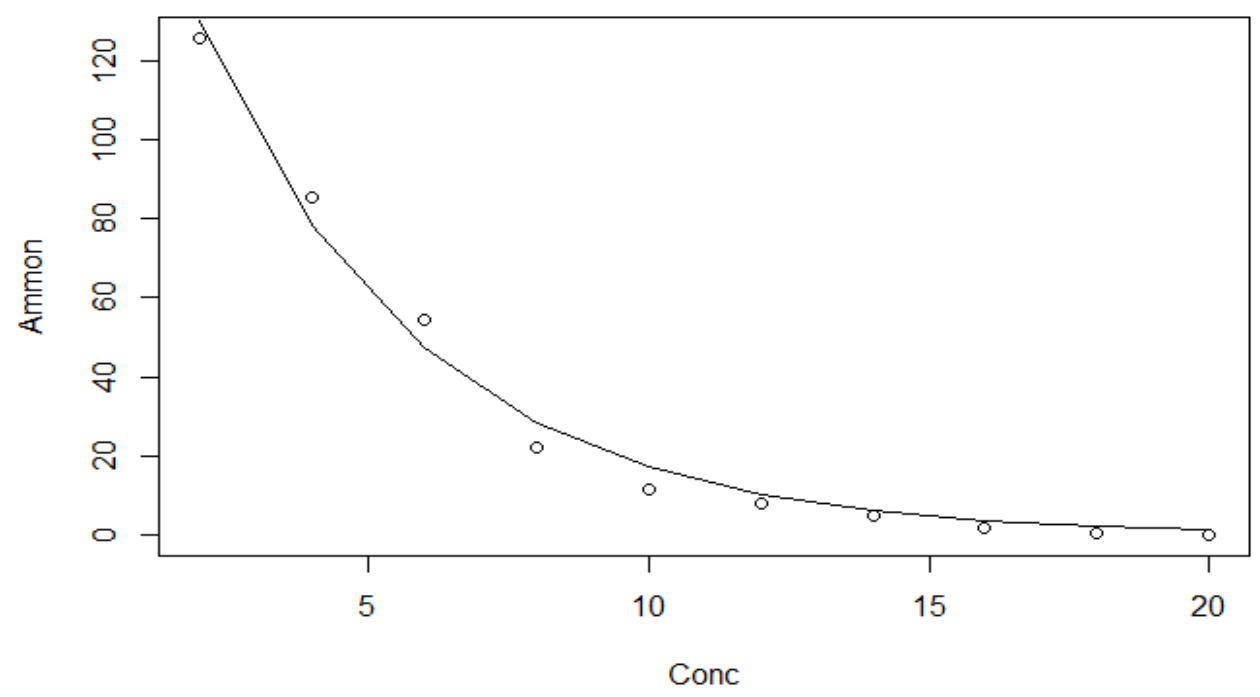

Figure 1. Effect of exogenous ammonium on nitrogenase activity in Rhizobium sp. strain 32H1 where observed results were depicted by dots and predicted results were depicted by lines.

Similarly, the effect of nitrate addition in the culture medium on the expression nitrogenase activity by Rhizobium species was evaluated. The amount of nitrate supplied in the culture medium as potassium nitrate, was further splitted into ten different concentrations with same trend of decrease in nitrogenase activity. Mathematical theories were used in these quantitative models to interpret observations and predictions are made (Table 2, Figure 2). Thus, using the graph presented in this model, the approximate values of nitrogenase activities (along $\mathrm{Y}$ axis) can be predicted at different concentrations of nitrate incorporated in the medium (along $\mathrm{X}$ axis).

\subsection{Effect of added nitrogenous fertilizers on shoot nitrogen content in two legume crops under field conditions}

Different legumes play an important role in sustainable agricultural production and contribute significantly towards nitrogen fixation in the soil every year. However, supplemental applications of nitrogenous fertilizer are required for intercropping or green mauring crops, which may constrain utility of intercropped legumes in these systems. Addition of higher amount of nitrate- and/or ammonium-containing fertilizers in soil were found to inhibit nodule formation resulting into reduced nitrogen fixation in soil.

Experiments performed under field conditions demonstrated that faba bean is more tolerant than chickpea to higher soil nitrate levels during crop rotations [14]. However, $\mathrm{N}_{2}$ fixation was not totally inhibited in either species at $150 \mathrm{~kg} \mathrm{~N}$ $\mathrm{ha}^{-1}$ level. Around 35 and $23 \%$ nitrogen fixation were maintained in chickpea in field and glasshouse, respectively (Table 3, Figure 3), whereas around $40 \%$ nitrogen fixation was maintained in faba bean in field and glasshouse conditions (Table 4, Figure 4).

Table 2. Effect of nitrate addition on nitrogenase activity in Rhizobium sp. strain $32 \mathrm{H} 1$ using predictive models developed using $\mathrm{R}$ software

\begin{tabular}{|c|c|c|}
\hline $\begin{array}{l}\text { Concentration } \\
\text { Nitrate }\left(\mathrm{KNO}_{3}\right)\end{array}$ & $\begin{array}{l}\text { Nitrogenase } \begin{array}{r}\text { activity } \\
{[\text { nmole acetylene }} \\
\text { reduced } \\
\text { protein })^{-1} \text { ] }\end{array} \\
\text { (mg }\end{array}$ & \multirow{11}{*}{ 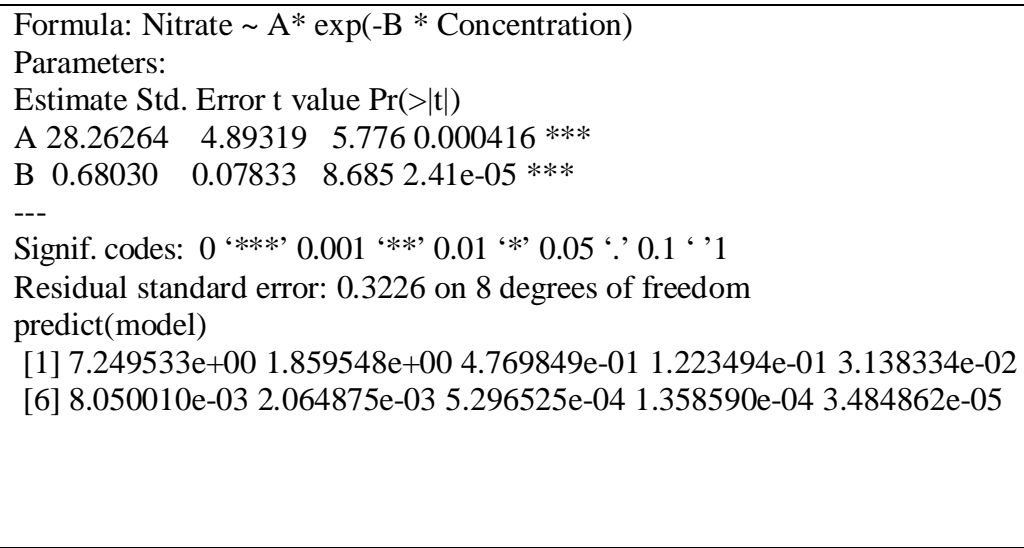 } \\
\hline 2.0 & 7.3 & \\
\hline 4.0 & 1.5 & \\
\hline 6.0 & 1.0 & \\
\hline 8.0 & 0.5 & \\
\hline 10.0 & 0.2 & \\
\hline 12.0 & 0.1 & \\
\hline 14.0 & 0.5 & \\
\hline 16.0 & 0.0 & \\
\hline 18.0 & 0.0 & \\
\hline 20.0 & 0.0 & \\
\hline
\end{tabular}




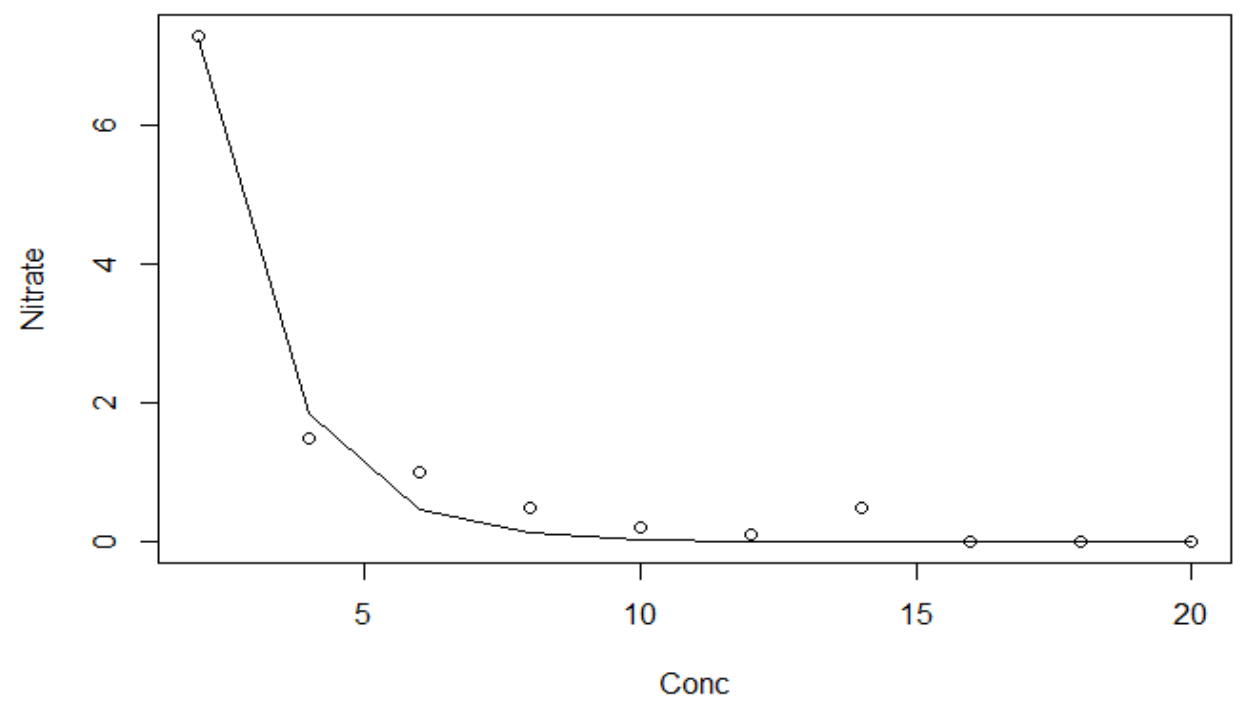

Figure 2. Effect of nitrate on nitrogenase activity ( $\mathrm{N}_{2}$ fixation) in Rhizobium sp. strain $32 \mathrm{H} 1$ where observed results were depicted by dots and predicted results were depicted by lines.

The following piecewise linear regression model [25]-[26], in which the two pieces are connected at $X=50$ (fertilizer nitrogen), was used for prediction of biological $\mathrm{N}_{2}$ fixation for fixation in chickpea (Table 3) and faba bean (Table 4):

$$
\mathrm{Y}_{\mathrm{i}}=\beta_{0}+\beta_{1} \mathrm{X}_{\mathrm{i} 1}+\beta_{2}\left(\mathrm{X}_{\mathrm{i} 1}-50\right) \mathrm{X}_{\mathrm{i} 2}+€_{\mathrm{i}}(\mathrm{i}=1,2,3, \ldots, \mathrm{n})
$$

where $Y_{i}$ is the $i^{\text {th }}$ observation of the response variable and

$\mathrm{X}_{\mathrm{i} 2}$ is a dummy variable defined as

$\mathrm{X}_{\mathrm{i} 2}=0$ if $\mathrm{X}_{\mathrm{i} 1} \leq 50$

$$
=1 \text { if } X_{i 1}>50
$$

Also, $€_{i}$ is the error term associated with the $i^{\text {th }}$ observation, which is assumed to follow the usual assumptions. The term $\left(\mathrm{X}_{\mathrm{i} 1}-50\right) \mathrm{X}_{\mathrm{i} 2}$ denote the interaction term.
In another set of experiments performed under field conditions, the doses of fertilizer addition in the soil were further splitted to fifteen different concentrations with same trend of decrease in shoot fix nitrogen content. Mathematical theories were used in these quantitative models to interpret observations and predictions are made about shoot fix nitrogen content in chickpea (Table 3, Figure 3). Thus, using the graph presented in this model, the approximate values of shoot nitrogen content in chickpea (along $\mathrm{Y}$ axis) can be predicted at different concentrations of fertilizer nitrogen applied in the soil (along $\mathrm{X}$ axis).

Table 3. Effect of fertilizer nitrogen addition on shoot nitrogen content in chickpea and development of predictive model

\begin{tabular}{|c|c|c|}
\hline $\begin{array}{l}\text { Fertilizer } \mathrm{N} \text { rate } \\
\left(\mathrm{Kg} \mathrm{N} \mathrm{ha}^{-1}\right)\end{array}$ & $\begin{array}{lrr}\begin{array}{l}\text { Shoot fix } \\
\text { content } \\
\left.\text { plant }^{-1}\right)\end{array} & & \begin{array}{r}\mathrm{N} \\
(\mathrm{mg}\end{array} \\
\end{array}$ & \multirow{17}{*}{ 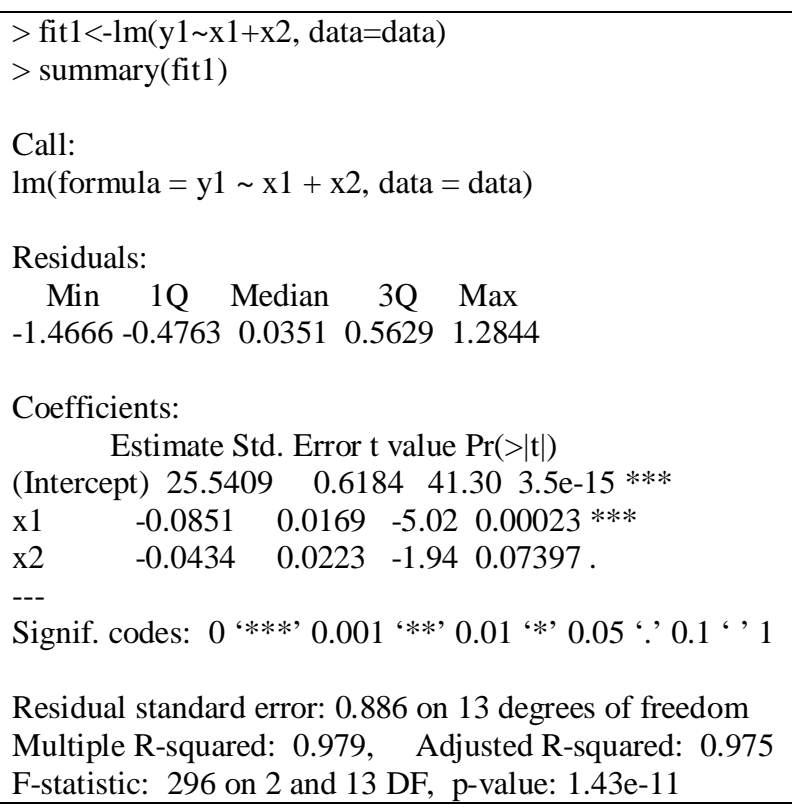 } \\
\hline 0 & 25.2 & \\
\hline 10 & 24.6 & \\
\hline 20 & 24 & \\
\hline 30 & 23.4 & \\
\hline 40 & 22.9 & \\
\hline 50 & 22.5 & \\
\hline 60 & 20.5 & \\
\hline 70 & 18.5 & \\
\hline 80 & 16.5 & \\
\hline 90 & 15 & \\
\hline 100 & 13.4 & \\
\hline 110 & 12.7 & \\
\hline 120 & 12 & \\
\hline 130 & 11.3 & \\
\hline 140 & 10.5 & \\
\hline 150 & 9.73 & \\
\hline
\end{tabular}
using $\mathrm{R}$ software 


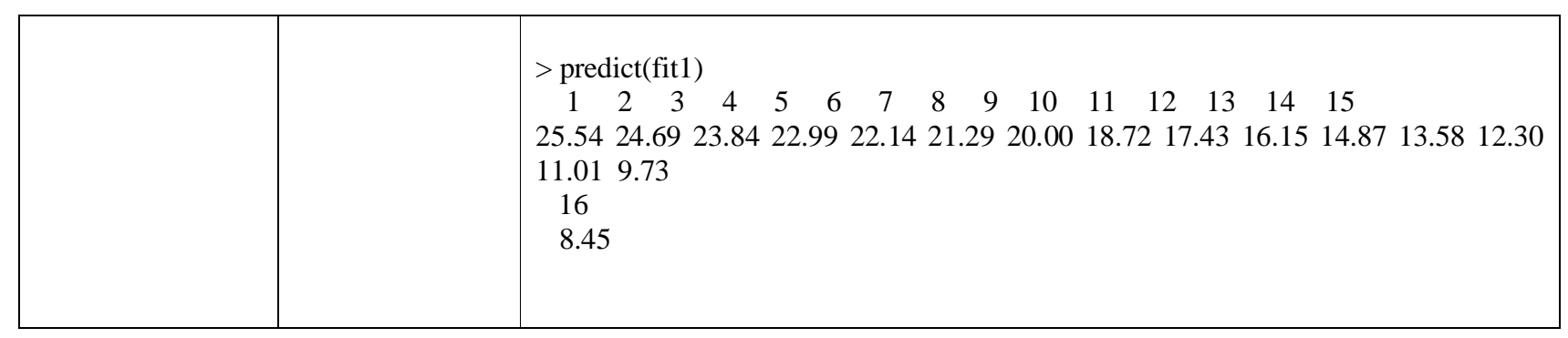

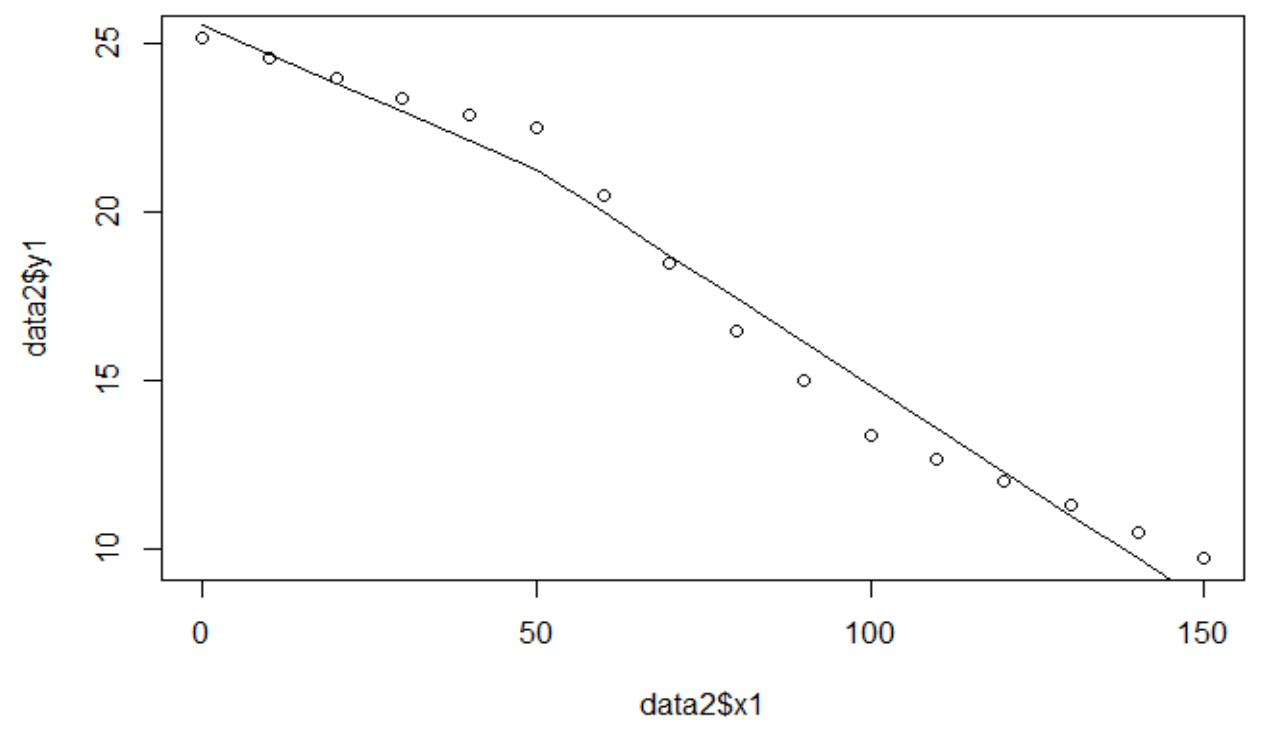

Figure 3. Observed results were depicted by dots and predicted results were depicted by lines, y1=Chickpea and $\mathrm{x} 1=$ concentration of nitrogen

Under field conditions, the doses of fertilizer addition in the soil cropped with faba bean were also further splitted to fifteen different concentrations. Mathematical theories were used in these quantitative models to interpret observations regarding decrease in shoot fix nitrogen content and predictions were made about correlation of fertilizer doses with shoot fix nitrogen content (Table 4, Figure 4). Thus, using the graph presented in this model, the approximate values of shoot nitrogen content in faba bean (along $\mathrm{Y}$ axis) may be predicted at different concentrations of fertilizer nitrogen applied in the soil (along $\mathrm{X}$ axis).

Table 4. Effect of fertilizer nitrogen addition on biological $\mathrm{N}_{2}$ fixation and shoot nitrogen content in faba bean and development of predictive model using R software

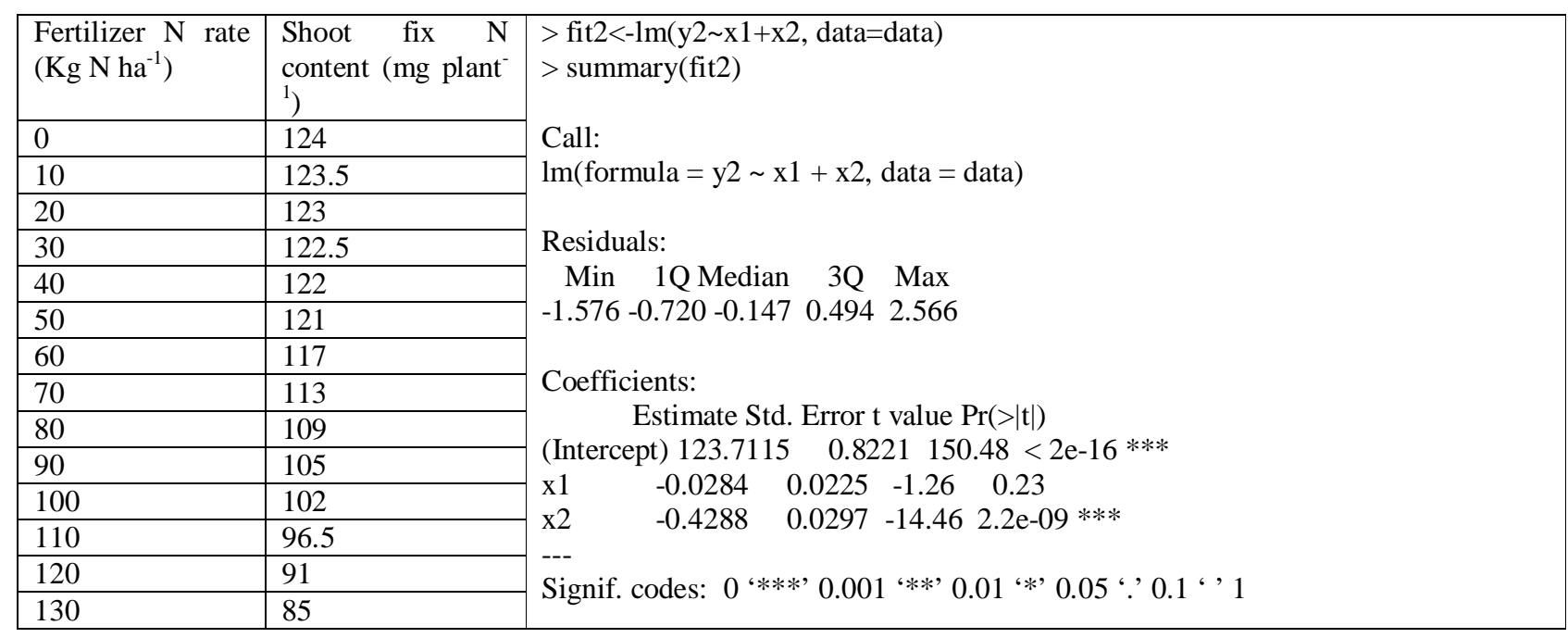




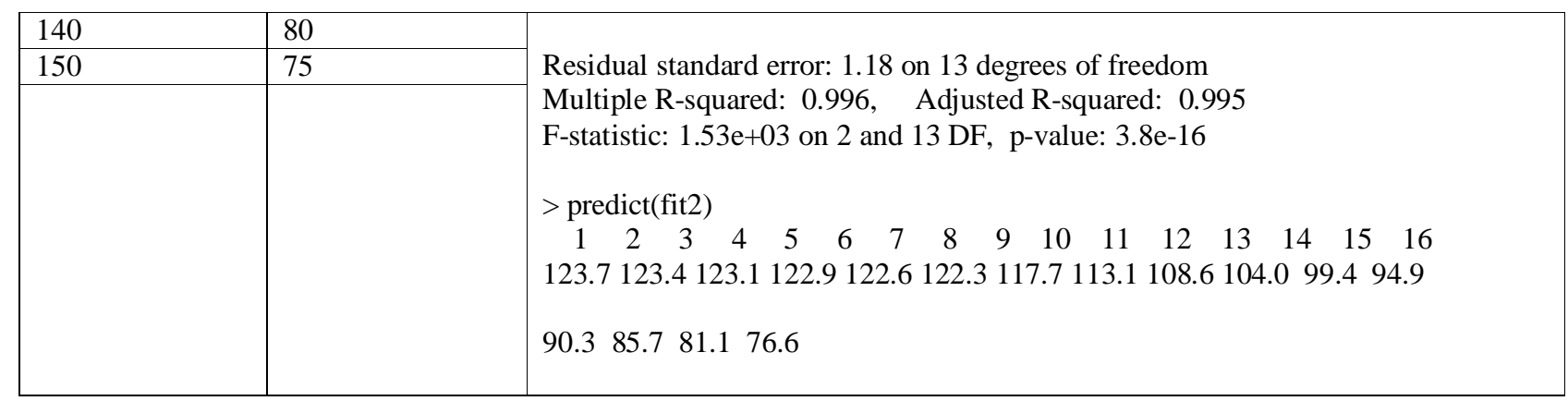

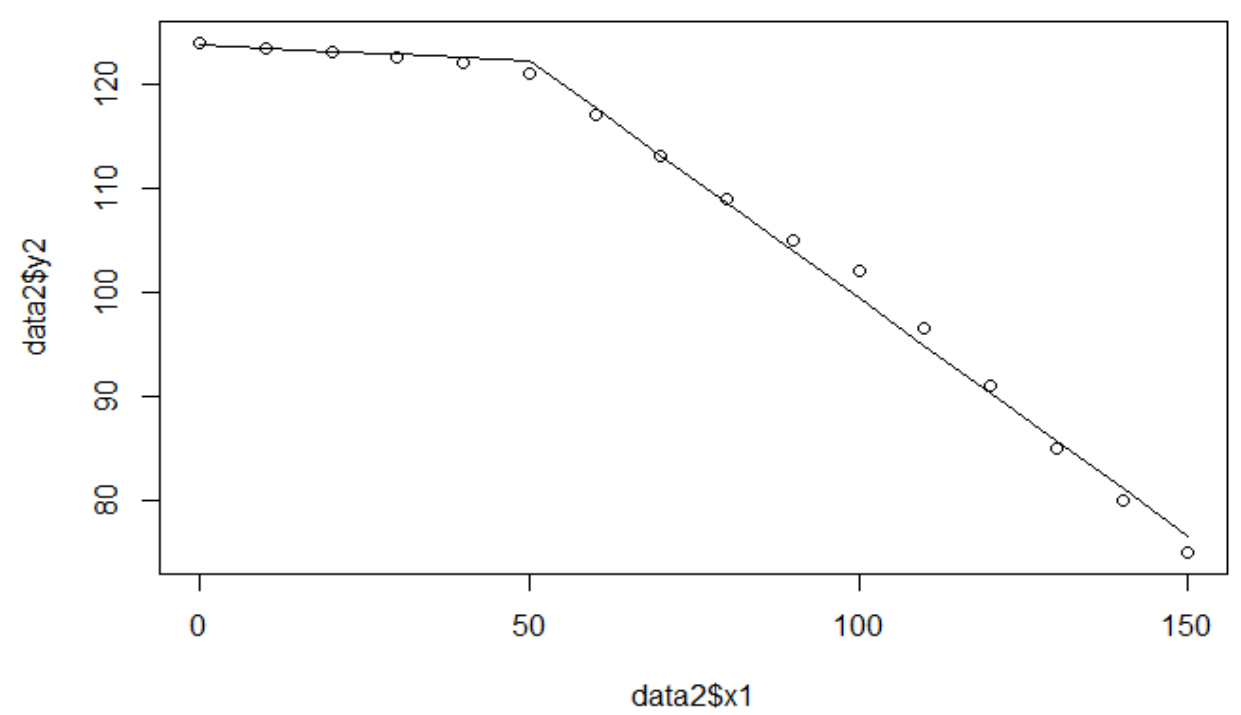

Figure 4. Observed results were depicted by dots and predicted results were depicted by lines, $\mathrm{y} 2=\mathrm{Faba}$ bean and $\mathrm{x} 1=$ concentration of nitrogen.

\section{DISCUSSION}

The concentration of combined nitrogen in the soil (supplied either as $\mathrm{NO}_{3}$ and $\mathrm{NH}_{4}{ }^{+}$as fertilizer) has been observed to down-regulate nitrogenase activity and $\mathrm{N}_{2}$ fixation under terrestrial ecosystems [27]-[28]. Similarly, concentrations of added nitrogen sources were found to influence growth and nitrogen fixation in Rhizobium species under cultural conditions [13]. The concentration of different nitrogen sources i.e., glutamine, ammonium sulphate and potassium nitrate were demonstrated to affect growth and nitrogenase activity of Rhizobium strain 32H1 under cultural conditions [13]. At $2 \mathrm{mM}-\mathrm{N}, \mathrm{NH}_{4}{ }^{+}$supported high levels of nitrogenase activity (Table 1; Figure 1), yet $\mathrm{NO}_{3}^{-}$addition supported only very low activity (Table 2; Figure 2). In the present studies, predictive models were developed for predicting nitrogen fixation by rhizobia in response to different nitrogen level conditions prevailing under cultural conditions using $\mathrm{R}$ software.

The amount of ammonium supplied in the medium as ammonium sulphate, was further splitted to ten different concentrations to develop quantitative models for predicting the effect of fixed $\mathrm{N}$ uptake and its influence on $\mathrm{N}_{2}$ fixation by Rhizobium species (Table 1, Figure 1). Observations of nitrogenase activity values under laboratory conditions were interpreted/splitted in these quantitative models and predictions were made regarding the approximate values of nitrogenase activities in relation to different concentrations of ammonium in the medium. In another predictive model, the amount of nitrate supplied in the culture medium as potassium nitrate, was further splitted to ten different concentrations with same trend of decrease in nitrogenase activity by Rhizobium species. Mathematical calculations were used in these quantitative models to interpret laboratory observations and predictions were made about effect of nitrate addition in the culture medium on the expression of nitrogenase activity by Rhizobium species (Table 2, Figure 2 ). Thus, using these predictive models, the approximate values of nitrogenase activities can be predicted at different concentrations of ammonium or nitrate in the medium.

Under glasshouse pots trial conditions, the impact of four rates of $\mathrm{N}$ fertilizer $(0,50,100$ and $150 \mathrm{~kg} \mathrm{~N}$ for every hactare) on nitrogen fixation was evaluated in faba bean and chickpea when cultivated as inter-row legume crops in Melaleuca alternifolia plantation [14]. Similarly predictive models were developed for the effect of fertilizer addition on the shoot fix nitrogen content under field conditions. The doses of fertilizer addition in the soil were further splitted to fifteen different concentrations and mathematical theories 
were used in these quantitative models to interpret observations about the effect of fertilizer doses on shoot fix nitrogen content in chickpea (Table 3, Figure 3). Thus, using this model, the approximate values of shoot nitrogen content in chickpea can be predicted at different concentrations of fertilizer nitrogen in the soil. Similarly, mathematical theories were used in to interpret observations regarding decrease in shoot fix nitrogen content in faba bean and predictions were made about correlation of fertilizer doses with shoot fix nitrogen content under field conditions (Table 4, Figure 4). Thus, the approximate values of shoot nitrogen content in chickpea and faba bean can be predicted at different concentrations of fertilizer nitrogen in the soil using these models. Such quantitative models have earlier been used to complement the laboratory experiments and in situ measurements of nitrogen fixation [15]-[16].

In similar studies, a coarse-grained model was developed for blue green algae Anabaena correlating its growth based on addition of various fixed $\mathrm{N}$ sources and the process of their assimilation into biomass. The model observed negative correlation between $\mathrm{NO}_{3}$ and $\mathrm{NH}_{4}{ }^{+}$uptake and $\mathrm{NifH}$ (nitrogenase iron protein) level and it also showed the inhibition of heterocyst differentiation by fixed $N$ [29]. Recently, a coarse-grained model developed for Azotobacter resolved fixed $\mathrm{N}$ uptake showing that the rate of $\mathrm{N}_{2}$ fixation is optimally regulated to maximize biomass concentration [30]. The model suggested that while using only the fixed $\mathrm{N}$ source for growth, this organism invested in high rates of respiration associated with respiratory protection. Similarly, the behaviour of nitrogen-fixing rhizobia could be predicted for nitrogen fixation in legume plants in response to available nitrogen level prevailing in the soil by use of these predictive models.

\section{CONCLUSION}

The optimal nitrogen fertilization doses and improvement of nitrogen management efficiency heavily depend on precise assessment of nitrogen status in plant-soil system [31]. To maximize benefits of nitrogen nutrition and to guarantee adequate nitrogen availability throughout growing season, extra nitrogen application in the form of chemical fertilizers may be required during growing season of various crops [1]. However, environmental nitrogen conditions are critical signals for regulation and expression of nitrogen fixation (nif and fix) genes in different nitrogen-fixing bacteria [32]. Due to environment-friendly and plant growth-promoting traits, application of biofertilizers (microbial inoculants) has emerged as an innovative technology for improving crop production [33, 34]. But global warming, changes in precipitation patterns and recent abrupt changes in climatic conditions have emerged as the major constraints for stagnation of productivity in cereal and legume crops [9, 35].

For development of any predictive model, proper experimental data obtained from laboratory and field experiments are essential. Thus, values obtained from the experiments conducted and used for development of models are usually complementary and provide useful information about quantitative measurements and mathematical theories. In this study, predictive models were developed to study the behaviour of rhizobia for nitrogen fixation in response to nitrogen level conditions prevailing under cultural conditions as well as in the soil using $\mathrm{R}$ software. Such predictive models will help to learn more about biological nitrogen fixation under culture and field conditions and may help to improve availability of fixed nitrogen for restoration of soil fertility and plant health leading to crop productivity improvement. Such predictive models can be expanded to cover different nitrogen-fixing organisms including terrestrial, marine, heterotrophic, aerobic and anaerobic nitrogen-fixing organisms. Further, the development of novel computer-based softwares, rapid development of predictive skill and the understanding of interactions between microbial ecosystems, biogeochemistry and climate is expected in near future to improve prediction of nitrogen fixation for improving crop production.

\section{ACKNOWLEDGMENT}

Authors thank Dr. B. K. Hooda, Professor, Deptt. of Mathematics \& Statistics, for his immense help in application of R software for development of predictive models. We also thank Dr. S. S. Sindhu, Professor, Deptt. of Microbiology, for his support and guidance rendered in analysis of the work related to Microbiology. Authors also thank the Shri JJT University, Jhunjhunu for providing the infrastructure required in completion of this research work.

\section{REFERENCES}

[1] P. Newbould. Use of nitrogen fertilizer in agriculture: where do we go sustainablely and ecologically?, Plant and Soil, vol. 115, pp. 297-311, 1989.

[2] D. Tilman, K.C. Cassman, P.A. Matson, R. Naylor and S. Polasky. Agricultural sustainability and intensive production practices, Nature, vol. 418, pp. 671-677, 2002.

[3] O.A. Fasusi, C. Cruz, and O.O. Babalola. Agricultural sustainability: Microbial biofertilizers in rhizosphere management, Agriculture, vol. 11, pp. 163, 2021. doi.org/10.3390/agriculture11020163

[4] J. Zhang, J. Cook, J.T. Nearing, J. Zhang, R. Raudonis, B.R. Glick, M.G.I. Langille and Z. Cheng. Harnessing the plant microbiome to promote the growth of agricultural crops, Microbiological Research, vol. 245, article 126690, pp. 1-14, 2021.

[5] J. Ishizuka. Trends in biological nitrogen fixation research and application, Plant and Soil, vol. 141, pp. 197-209, 1992.

[6] R.H. Burris and G.P. Roberts. Biological nitrogen fixation, Annual Review of Nutrition, vol. 13, pp. 317335, 1993.

[7] J.E. Thies, P.W. Singleton and B.B. Bohlool. Influence of size of indigenous rhizobial populations on establishment and symbiotic performance of introduced rhizobia on field-grown legumes, Applied and Environmental Microbiology, vol. 57, no. 1, pp. 19-28, 1991.

[8] C. Franche, K. Lindström and C. Elmerich. Nitrogenfixing bacteria associated with leguminous and nonleguminous plants, Plant and Soil, vol. 321, no. 1-2, pp. 35-59, 2009.

[9] M. Grover, S.Z. Ali, V. Sandhya, A. Rasul and B. Venkateswarlu. Role of bacteria in adaptation of agriculture crops to abiotic stresses, World Journal of 
Microbiology and Biotechnology, vol. 27, no. 5, pp. 1231-1240, 2011.

[10] P.M. Vitousek, D.N.L. Menge, S.C. Reed, C.C. Cleveland. Biological nitrogen fixation: rates, patterns and ecological controls in terrestrial ecosystems, Philosophical Transactions Royal Society B: Biological Sciences, vol. 368, 20130119, 2013.

[11] D.N. Smercina, S.E. Evans, M.L. Friesen and L.K. Tiemann. To fix or not to fix: Controls on free-living nitrogen fixation in the rhizosphere, Applied and Environmental Microbiology, vol. 85, e02546-18. doi.org/10.1128/AEM.02546-18. 2019

[12] J. Streeter. Inhibition of legume nodule formation and $\mathbf{N}_{2}$ fixation by nitrate, Critical Review in Plant Sciences, vol. 7, pp. 1-23, 1988.

[13] C.E. Pankhurst and A.S. Craig. Effect of oxygen concentration, temperature and combined nitrogen on morphology and nitrogenase activity of Rhizobium sp. strain $32 \mathrm{H1}$ in agar culture, Journal of General Microbiology, vol. 106, pp. 207-219, 1978.

[14] T.J. Rose, C.C. Julia, M. Shepherd, M.T. Rose and L. van Zwieten. Faba bean is less susceptible to fertilizer $N$ impacts on biological $N_{2}$ fixation than chickpea in monoculture and intercropping systems, Biology and Fertility of Soils, vol. 52: pp. 271-276, 2010.

[15] K. Inomura, C. Deutsch, T. Masuda, O. Prášil and M. J. Follows. Quantitative models of nitrogen-fixing organisms, Computational and Structural Biotechnology Journal, vol. 18, pp. 3905-3924. doi.org/10.1016/j.csbj.2020.11.022. 2020.

[16] C. Pucciariello, A. Boscari, A. Tagliani, R. Brouquisse and P. Perata. Exploring legume-rhizobia symbiotic models for waterlogging tolerance, Frontiers in Plant Sciences, vol. 10, Article 578, 09 pages. doi: 10.3389/fpls.2019.00578. 2019.

[17] R. Dixon. Stranglehold on transcriptional activator by its partner regulatory protein - case of NifL-NifA two component regulatory system, In: SGM Symposium 61: Signals, switches, regulons and cascades: control of bacterial gene expression, D.A. Hodgson and C.M. Thomas, Eds., Cambridge University Press, 2002, pp. 213-230.

[18] D. Sindhu. Data mining and in silico modeling of nitrogen fixation NifA protein in nodule-forming rhizobia using Bioinformatics tools, $\mathrm{Ph}$. $\mathrm{D}$. dissertation, Deptt. of Computer Science \& Engineering, Shri Jagdishprasad Jhabarmal Tibrewala University, Jhunjhunu, Rajasthan, India, 2020.

[19] D. Sindhu, S. Sindhu and S. K. Yadav. Data mining and phylogenetic analysis of nifA gene sequences using nodule-forming Azorhizobium strain, International Journal of Emerging Trends and Technology in Computer Sciences, vol. 10, pp. 1-8, 2021.

[20] R Development Core Team. R: language and environment for statistical computing. $R$ Foundation for Statistical Computing, Vienna, Austria. ISBN: 3900051-07-0. 2012.

[21] C.C. Cleveland, A.R. Townsend, D.S. Schimel, H. Fisher, R.W. Howarth and L.O. Hedin, et al. Global patterns of terrestrial biological nitrogen $\left(\mathbf{N}_{2}\right)$ fixation in natural ecosystems, Global Biogeochemical Cycles, vol. 13, pp. 623-645, 1999.

[22] M.J. Follows and S. Dutkiewicz. Modeling diverse communities of marine microbes, Annual Review of Marine Sciences, vol. 3, pp. 427-451, 2011.

[23] B. Le Lin, A. Sakoda, R. Shibasaki, N. Goto and M. Suzuki. Modelling a global biogeochemical nitrogen cycle in terrestrial ecosystems, Ecological Modelling, vol. 135, pp. 89-110, 2000.

[24] Y.P. Wang, B.Z. Houlton and C.B. Field. A model of biogeochemical cycles of carbon, nitrogen and phosphorus including symbiotic nitrogen fixation and phosphatase production, Global Biogeochemical Cycles, vol. 21, pp. 1-15, 2007.

[25] S.E. Ryan. A tutorial on the piecewise regression approach applied to bedload transport data, General Technical Report RMDS-GT12-189. Fort Collins, CO: U.S. Deparment of Agriculture, Forest Service, Rocky Mountain Research Station. 2007.

[26] S. Kumar, B.K. Hooda, R. Singh and S. Jaggi. Use of dummy variables for investigating structural stability in fertiliser-yield response models, Indian Journal of Agricultural Sciences, vol. 78, no. 2, pp. 183-186, 2008.

[27] T. Bühler, R. Sann, U. Monter, C. Dingier, J. Kuhla and J. Oelze. Control of dinitrogen fixation in ammonium-assimilating cultures of Azotobacter vinelandii, Archieves of Microbiology, vol. 148, pp. 247-251, 1987.

[28] C.M. Holl and J. Montoya. Interactions between nitrate uptake and nitrogen fixation in continuous cultures of the marine diazotroph Trichodesmium (cyanobacteria), Journal of Phycology, vol. 41, pp. 1178-1183, 2005.

[29] F.L. Hellweger, N.D. Fredrick, M.J. McCarthy, W.S. Gardner, S.W. Wilhelm and H.W. Paer. Dynamic, mechanistic, molecular-level modeling of cyanobacteria: Anabaena and nitrogen interaction, Environmental Microbiology, vol. 18, pp. 2721-2731, 2016.

[30] K. Inomura, J. Bragg, L. Riemann and M.J. Follows. A quantitative model of nitrogen fixaion in the presence of ammonium, PLoS One, vol. 13, e0208282. 2018.

[31] N.A. Di Benedetto, M.R. D. Corbo Campaniello, M.P. Cataldi, A. Bevilacqua, M. Sinigaglia and Z. Flagella. Role of plant growth promoting bacteria in improving nitrogen use efficiency for sustainable crop production: focus on wheat, AIMS Microbiology, vol. 3, no. 3, pp. 413-434, 2017.

[32] S. Sindhu, N.S. Redhu, D. Sindhu and S.K. Yadav. Computational analysis of phylogenetic diversity and evolutionary relationships using nifH gene sequences among nitrogen-fixing organisms, International Journal of Engineering Research and Technology, vol. 10, no. 2, pp. 249-257, 2021.

[33] M.S. Santos, M.A. Nogueira and M. Hungria. Microbial inoculants: reviewing past, discussing present and previewing outstanding future for use of beneficial bacteria in agriculture, $A M B$ Express, vol. 9, pp. 205, 22 pages. doi.org/10.1186/s13568-019-0932-0. 2019.

[34] D. Kour, K.L. Rana, A.N. Yadav, N. Yadav, M. Kumar and V. Kumar. Microbial biofertilizers: bioresources 
Divya Sindhu et al., International Journal of Advanced Trends in Computer Science and Engineering, 10(4), July - August 2021,2704 - 2713

and eco-friendly technologies for agricultural and environmental sustainability, Biocatalysis and Agricultural Biotechnology, vol. 23, 101487. doi.org/10.1016/j.bcab.2019.101487. 2020.

[35] S.B. Clair, and J.P. Lynch. Opening of Pandora's Box: climate change impacts on soil fertility and crop nutrition in developing countries, Plant and Soil, vol. 335, no. 1-2, pp. 101-115, 2010. 